\title{
Policy Analysis on Financing Roles for Population- and Individual-based Health Services in Light of the Universal Health Care Act
}

\author{
Leonardo R. Estacio, Jr., MCD, MPH, PhD, ${ }^{1,2}$ Christine Mae S. Avila, MD, ${ }^{1}$ \\ Ma-Ann M. Zarsuelo, RND, MSc, ${ }^{1,3}$ Ma. Esmeralda C. Silva, MPAf, MSPPM, PhD, 1,4 \\ Michael Antonio F. Mendoza, DDM, MA ${ }^{1,5}$ and Carmencita D. Padilla, MD, MAHPS 6 \\ ${ }^{1}$ University of the Philippines Manila Health Policy Development Hub \\ ${ }^{2}$ College of Arts and Sciences, University of the Philippines Manila \\ ${ }^{3}$ Institute of Health Policy and Development Studies, National Institutes of Health, University of the Philippines Manila \\ ${ }^{4}$ College of Public Health, University of the Philippines Manila \\ ${ }^{5}$ College of Dentistry, University of the Philippines Manila \\ ${ }^{6}$ University of the Philippines Manila
}

\begin{abstract}
Objectives. The health financing scheme brought by the Universal Health Care Act has a significant change in the landscape of allocating funds for health services, as well as in the delineation of roles among the key actors. Consistent with the law, the protection from the health financial risks of Filipinos must be guaranteed. This study aimed to determine the roles of the government and other key agencies in financing population-based and individual-based health services in the Philippines.
\end{abstract}

Methods. A systematic review of literature was done to generate evidence for the policy brief and proposed policy alternatives. The UP Manila Health Policy Development Hub organized a roundtable discussion in collaboration with the Department of Health participated by key stakeholders from various sectors involved in the policy issue. Systematic review and insights from the discussion were analyzed to produce consensus policy recommendations.

Results. Given the current procurement and financing, the DOH should fund population-based services while PhilHealth, with the assistance of Health Maintenance Organizations (HMO) for premium holders, should fund individual-based services. Health programs with grey areas (i.e. with both individual- and population-based services) need further technical discussions. It is imperative to have clear-cut specific guidelines on the managerial and financial roles of the provincial health board and the scope of financing service delivery.

Conclusion. Delineating the roles of $\mathrm{DOH}$, PhilHealth, and HMOs in financing health services is not without risks. The utilization of the special health fund at the provincial level should be carefully implemented and monitored to minimize inefficiencies and fraud.

Key Words: Universal Health Coverage, Healthcare financing, Health Insurance

\section{INTRODUCTION}

Financial protection is an essential part of universal health coverage. Structured and well-delineated health financing roles ensure optimal utilization of health services while protecting the population from financial catastrophe.

In 1995, Republic Act (RA) 7875 or the National Health

Corresponding author: Ma-Ann M. Zarsuelo, RND, MSc UP Manila Health Policy Development Hub

National Institutes of Health

University of the Philippines Manila

623 Pedro Gil St., Ermita, Manila 1000, Philippines

Email: mmzarsuelo@up.edu.ph
Insurance Act (NHIA) established the Philippine Health Insurance Corporation (PHIC), or PhilHealth, which sought to provide all Filipinos with financial access to health services giving particular priority to indigent sectors. ${ }^{1}$ PhilHealth was 
Financing Roles for Health Service Provision

intended to reduce out-of-pocket (OOP) expenses, which accounted for more than half of the total expenditures in health (53.9\%). ${ }^{2}$ Later reforms such as the Health Sector Reform Agenda in 1999, FOURmula ONE (F1) for Health in 2005, and Health-Care Financing Strategy 2010-2020 aimed to improve service delivery and health financing for PhilHealth and the Department of Health (DOH). These reforms sought to use $\mathrm{DOH}$ policies to ensure the quality of services and proper resource allocation at all levels of care. These also expanded PhilHealth coverage for maximal and equitable financial protection. ${ }^{3}$

In 2017, premium contributions to PhilHealth were $\mathrm{PhP} 106.6$ billion, which is $3 \%$ higher than the previous year. The largest contributor with $46 \%$ share is the formal economy, followed by $44 \%$ from the subsidized premium contributions of indigents, senior citizens from Sin Tax with, $7 \%$ from informal economy, and 3\% from the Sponsored Program. ${ }^{4}$ This gives a preview on the service coverage of the national insurance. In 2018, about $98 \%$ or 104.49 million Filipinos enjoyed PhilHealth coverage from the 93\% coverage from 2017. Out of the 2018 coverage, 33\% were indigents enrolled under the National Household Targeting System for Poverty Reduction (NHTS-PR) while around 9\% were senior citizens. ${ }^{5}$ The increasing coverage has been observed through the years but dissecting the contribution of out-of-pocket health expenditures, its proportion is still significant to the households' total expenses. The proportion of OOP health expenditures is directly associated with the magnitude of impact on the household's economic security. Hence, the effect of increasing OOP expenses is pronounced among the economically marginalized group. This affects their health-seeking decisions which might forgo critical prevention screenings and compliance to medications due to high cost. Further, redistribution of income due to catastrophic health expenditure will force the household to sacrifice basic needs, disrupting the living standards. ${ }^{6}$

The provisions of the Universal Health Care Act (Chapter II Section 7) classify the entitlements and stipulate the financing roles of the Department of Health, the Local Government Units (LGUs), and the Philippine Health Insurance Corporation on health services and interventions (individual and population-based). ${ }^{7}$ Finances for population-based services shall be free at point-of-service and will be financed by the National Government through $\mathrm{DOH}$ with support from LGUs. Funds for individualbased services should come from prepayment mechanisms such as social health insurance, private insurance, and Health Maintenance Organizations (HMOs) to ensure predictability of out-of-pocket expenses. ${ }^{8}$ The DOH Annual Report in 2018 indicated that from the $\mathrm{PhP} 106$ Billion total budget allocation for health, $35 \%$ goes to the preventive and promotive health care services while $49 \%$ for access to curative and rehabilitative care. ${ }^{5}$

\section{METHODS}

\section{Pre-work research}

A systematic review of literature was done to generate discussion points for the stakeholders' forum and to generate evidence for the policy recommendations. An electronic search regarding health financing roles and the experiences among different countries was done using the PubMed database. Keywords used in the search include "Healthcare Financing" [MeSH] OR "Health Financing", "Universal Health Insurance [MeSH] OR "Universal Health Coverage" which yielded 755 articles. Titles and abstracts of pertinent articles were screened based on titles, abstracts, and relevance, respectively. Based on applicability to local settings, three full-text articles were included. To pool more relevant resources, bibliographies of the eligible articles were reviewed. Official websites of the Department of Health and PhilHealth were also searched for official reports yielding to seven reports and one news article. Lastly, the Official Gazette was searched for copies of pertinent laws, yielding three records. A total of 15 full-text records were included in the review, dated 2007 to 2018.

The findings of the literature review were utilized in crafting the policy brief presented during the roundtable discussion (RTD). One of the inputs requested by the Department of Health, as the primary agency, is to review country experience in health financing. This aims to gather the strengths and weaknesses of local and international experience in financing health services.

\section{Philippine experience in health financing}

The enactment of the UHC Act brings forth change in financing schemes of health services; hence purchaser and provider roles in service delivery should be clear to avoid overlaps and to ensure that the bearer of the roles is fully capacitated, both technically and financially. As the Law aims to protect all Filipinos against health-related financial risk and to give them access to a comprehensive range of quality health services, evidence-based policy development must be practiced to adopt best practices at the local context and to mitigate current gaps. In the payer's perspective of PhilHealth, this will pave the way for minimizing OOP health expenditures across all PhilHealth member categories. It is important to note though, in a societal perspective which includes patient transportation and productivity loss due to the disease, determinants of total OOP expenditures should also be assessed at the demand side of the service delivery. In the study of Tobe et al. on PhilHealth claims in Benguet province and Baguio City, factors with a significant association with OOP expenditures and its amount includes age and residential location, disease severity, and membership type. ${ }^{9}$

PhilHealth, as the bearer of the National Health Insurance Program (NHIP) plays a decisive role in implementing the financing scheme of health services, particularly individual- 
based. Service coverage depends on the member classification. In 2018, the reported support value, or the proportion of hospital costs covered by PhilHealth, was $42 \%$ with an average value paid per claim (AVPC) of PhP 9,652.00. One of the PhilHealth programs is the No-Balance Billing (NBB) policy that allows members who are indigents, senior citizens, domestic workers, sponsored, and lifetime members to have zero copayments in admission in any PhilHealth accredited public hospital, even if total hospital bill exceeds the all case rates (ACR) since any excess will be billed to the hospitals' revenues. ${ }^{10}$ In 2018 , it was reported that $82 \%$ of NBB-eligible PhilHealth members had no out-of-pocket expenses for their hospital admissions. ${ }^{5}$ Implementation of UHC Act will move towards the realization of a hundred percent coverage for all Filipinos across different membership. Stipulated in Chapter II Section 9 of the Act entitled all Filipinos of immediate eligibility for PhilHealth benefit packages wherein no co-payment is charged for services in basic or ward accommodation (UHC Act). ${ }^{7}$

For five years, Sin Tax incremental revenues have been utilized for the national health budget. In 2018, PhP 71.2 billion constituting 67\% of DOH's total budget were allocated to enrollment and coverage in PHIC, strengthening preventive health programs, health awareness, medical assistance, financial assistance for Health Facility Enhancement Program, and service delivery networks. ${ }^{5}$

Other important strategies to cover Filipinos against financial risk are to streamline and harmonize access to several fund pools to avoid inefficient overlaps in health financing. An interim measure implemented in the Philippines was the issuance of the Joint Administrative Order No. 2018-0001 entitled "Streamlining Access to Medical Assistance Funds of the Government" by the DOH, the Philippine Charity Sweepstake Office (PCSO), Department of Social Welfare and Development (DSWD), and PhilHealth. This policy aimed to define the clear roles of the aforementioned agencies in enhancing the NBB policy for services such as case rates and Z-benefit packages, as well as formulating a streamlined process for utilizing the benefits of the PhilHealth member's dependents. ${ }^{8}$ Since PhilHealth reimbursement is one of the major sources of revenue of public healthcare providers, provision of disease prevention and health promotion such as vaccines, maternal and childcare services, and family planning services, that would augment benefits and provide a comprehensive range of services. ${ }^{5}$ This scenario was raised if funding will be transferred to PhilHealth. It is important to note though that NBB does not cover discharge medications. Hence, a similar burden of outpatient drugs is shared with non-NBB PhilHealth members. ${ }^{11}$ Transferring funds to PhilHealth for medication could also be explored given its significant share in out-of-pocket spending of Filipinos.

\section{International experience in health financing}

Before 1974, Thailand began establishing a social health insurance scheme called universal coverage scheme (UCS) available through a fee exemption system among poor segments of the population. The UCS expanded through the years and was eventually implemented nationwide in 2001 . The UCS is tax-financed and is free at the point of service. It includes a comprehensive package with a primary care focus. However, the UCS was challenged by the following concerns: (1) identifying the uninsured population due to lack of a database for beneficiaries of its prior insurance scheme; (2) confusing service provider payment standards; and (3) unclear contracting mechanism of service providers. The Thai government was able to address these, first, by establishing a government registration database to identify the uninsured persons and to avoid duplication of benefit packages. Then, costing exercises were conducted to set payment standards for health care providers. Lastly, Thailand eventually set its contracting mechanism based on its existing social security scheme (SSS). ${ }^{12}$ Thailand was able to attain universal health coverage by 2002 . However, the implementation still faces challenges in terms of financial sustainability and merging its existing schemes into a singular fund. Despite the financial and political conflicts, the universal health scheme is still heralded for its perspective on the population's "right to health."13

In Vietnam, preventive care subsidies are capitationbased. Capitation is described as being paid by the health insurance fund every month per enrolled patient regardless of the number of treatment and type of treatment. ${ }^{13}$ Capitation ensures containment of cost and transfers the financial risk to health service providers in contrast to the fee-for-service system used by PhilHealth, which transfers financial risk to its members through balance billing. ${ }^{14}$ The disadvantage in capitation is the risk of inadequate service delivery so that unit costs and rates of use should be monitored, and members should be allowed to change contractors annually if they are not satisfied. ${ }^{15}$

\section{Conduct of roundtable discussion}

The UP Manila Health Policy Development Hub (UPM HPDH), in collaboration with the Department of Health, conducted an RTD on the Universal Health Care Act entitled "Health service and financing roles: Populationbased and individual-based" held on the $6^{\text {th }}$ of December 2018 at the Philippine General Hospital, Manila. Twentyfive discussants participated as key representatives from the national government agencies (NGAs), local government units (LGUs), professional societies, non-government organizations, and the academe to share insights and expertise on different aspects of financing in health service delivery and universal health coverage.

The policy RTD aimed to reach a consensus set of policy recommendations as inputs in the Implementing Rules and Regulations of the UHC Law. Given the diversity of discussants, key resource speakers gave presentations in the first half of the event to provide background knowledge on the current scientific and legal evidence. A member of UPM 
HPDH outlined the past and present policies for improving health financing by $\mathrm{DOH}$ and PHIC and presented the discussion questions. Key resource speaker from PhilHealth gave an overview of the existing system on financial coverage of health services, costing initiatives, and the roadmap to shifting from the All Case Rates (ACR) system to Disease-Related Groups-Global Budget (DRG-GB). For ground experiences in the health system, a former Secretary of Health shared the policy gaps and barriers in health service delivery in a municipality in Eastern Samar.

During the deliberation of UPM HDPH, the research team, and the $\mathrm{DOH}$ as the primary agency, options in financing schemes were explored which included transferring services and commodities to PhilHealth versus retaining the current set-up, which is funded by $\mathrm{DOH}$. This was driven by the overlap of healthcare provision. Hence, the policy discussion was guided by the following questions:

1. What are the strengths and weaknesses in the current service delivery network (SDN) concerning financing roles of DOH, PhilHealth, Local Government Units (LGUs)?

2. What emerging, good, and best practices can be drawn or considered?

3. Based on the UHC Bill delineation of financing roles and the strengths and weaknesses of financing SDN, what are the roles of government agencies and LGUs in population- and individual-based health services?

From the thematic analysis of the policy RTD and review of literature, the policy paper was crafted. The draft was circulated among the participants for comments and/or approval. Inputs were all consolidated for revision which was reviewed by the UPM HDPH members.

\section{RESULTS AND DISCUSSION}

The policy discussion served as an avenue to share varying perspectives, leading to productive deliberation on the varying level of agreements and disagreements. The UPM HPDH served as the arbiter of arising policy issues and concerns were directed to appropriate national government agencies for further clarifications. Results were thematically analyzed based on the locus of implementing financing health services.

\section{Risks and Proposed Mitigating Measures if services are transferred to PhilHealth versus retained in the DOH}

Transferring services or commodities procurement from the Department of Health to PhilHealth aids in the delineation of financing roles, but it is not without risks.

One risk would be escalating costs. Transfer of services to PhilHealth may lead to excessive delivery of services if there is inadequate or inappropriate regulation. Moreover, it is easier to increase social contributions than to reduce benefits because members feel that they have paid for their benefits. These tendencies have been observed in countries with extensive experience in social health insurance. For these reasons, countries usually spend more on health when shifting services to social health insurance. ${ }^{13}$ Other things to consider would be the capacity of PhilHealth to shoulder new costs and resources including human capital and operating expenses for purchasing or even procurement of commodities like medications, vaccines, etc.

An increase in service that PhilHealth covers mean an increase in the contribution by its members. In countries where product and labor markets are not very competitive, employers may not be able to reduce salaries to compensate for a rise in payroll contributions to PhilHealth in the short run. Thus, social insurance contributions may increase labor costs and consequently lead to unemployment. On a larger scale, this may reduce the competitiveness of a country, dissuade investments and slow down the growth of the economy. Moreover, if the government is a major employer or manager, elevated payroll contributions will significantly contribute to and increase public expenditures. ${ }^{15}$

The success of the implementation of the social health insurance system in developing countries depends on the presence of several preconditions and governments' abilities to influence its implementation. In relation to addressing the negative impact of increased payroll contributions, it has been documented that it is easier to absorb new contributions in countries with prosperous economic growth. It is necessary to assess the extent to which amplified wages due to payroll-based contributions affect the competitiveness of a certain economy. In developed countries like France, social contributions have led to high levels of unemployment. Consequently, a major reform in the financing of the social insurance system intended to reduce the weight of deductions from payroll was implemented. Employees' contributions were transformed into a tax on all sources of income, which included salaries, social benefits, capital gains, and gambling income. ${ }^{12}$

Poor coverage for chronic diseases and preventive services like immunizations can be addressed by ensuring cooperation and coordination between the providers of such services. Initial steps should be done to first maintain a good system for providing primary care services and the corresponding benefit packages from PhilHealth (e.g. immunizations and screening). Private providers should be required to adhere to the social insurance systems' rules and should be given appropriate incentives. In covering for chronic diseases, the most necessary services (diagnostics and laboratories), medications and pre-determined number of consultations per professional needed should be outlined. It may require initially a general increase in contributions and may also be covered by other financial sources like co-payments and coinsurance for last peso coverages, but in the long run, may be covered as a whole if more budget allocation and proper utilization will be implemented. 
For the escalating costs, it is always imperative to determine whether the capacity to run a certain system, in this case, a social insurance system with coverage for all, is adequate before truly establishing them. To provide universal health care may entail a significant amount of budget, which will likewise convert to massive expenditure. This will require extensive cost evaluation and analysis and more importantly, political will.

\section{Clarifying the Financing Roles}

Once all health services have been classified into population-, individual-based or grey area, the financing roles of the various stakeholders will be clearly defined in the UHC Act IRR. There is, however, a need to clarify the use and allocation of the special health funds at the LGU level, particularly at the provincial level. Questions raised during the discussion were: (a) what part of the special health fund will be from DOH or PHIC?; and (b) will there be specific services and commodities allotted in each fund source?

These bring forth suggestions in the IRR, wherein barangays or the municipal level units submit their budget proposal to the local health boards, which will subsequently be deliberated upon by the provincial special health fund body. The accountability is at the province level which must have reasonable flexibility to manage funds. Another concern raised was that the local government units may opt-out of the service delivery network. To avoid ambiguity in the inclusion/membership in SDNs, the UHC law IRR must then need to have clear provisions addressing these.

It was also raised by the discussants that while the UHC Act does not mandate membership of the local health systems to the new scheme, all local health systems shall be integrated after six (6) years through the issuance of an Executive Order, upon positive recommendation by the independent study to be conducted by the Joint Congressional Oversight Committee on UHC and positive recommendation by the Secretary of Health. It is, therefore, necessary that efforts be made by all LGUs, with assistance from DOH, during the transition phase.

Other issues raised to be resolved relate to corporate or formal sector employees who have HMO coverage; wherein PhilHealth pays for the first peso, while the HMOs could cover up to the last peso depending on the Service Agreement. Should the HMO coverage be extended to cater to a greater segment of the population, or should there be designated specific services for HMO coverage only? Similarly, additional amenities would be accessible for those who can afford HMOs. It is important to note though that the minimum quality and standard of health services should be equal regardless of the facility or HMO coverage.

Delegation of service provision from national agencies to the service providers at the local government units stirred questions. If the $\mathrm{DOH}$ programs will be divided into components (preventive, promotive, curative, rehabilitative), what components will be mainly delegated to the service providers of the province-wide health system? If the service providers will manage both the health program and funds, how can their competencies in doing such be guaranteed? This opened questions on the role of HMOs in funding medicines. HMOs can complement PhilHealth in covering for prescribed drugs that are not under the Philippine National Drug Formulary, provided that the overall hospital cost (e.g. outpatient, inpatient, emergency care) is within the maximum benefit limit determined by the amount of premiums paid.

The roundtable discussion focused on clarifying individual-based and population-based health services and who will ultimately finance these. The major stipulation of the UHC law is that individual-based services will be funded by PhilHealth and the population-based services will be funded by the Department of Health. However, it should be recognized that health programs are multifaceted such that it may have several components which may be individual-, population-based, or grey areas. These grey areas should be specifically considered in delineating financing roles for the implementing rules and regulations of the UHC law.

The discussion recognized the need for facilitation of a stable health information system to support evidencebased interventions. There is also a need to involve the private health facilities in the health service delivery network and subsequently be integrated with the public health services. Also, the concept of local health boards as the main stakeholders for the allocation of health funds is a crucial aspect of the UHC law, and there should be specific rules on who shall manage these. Lastly, there is a recurring thought on how the provincial health board will manage the SHF and what mechanisms should be in place to monitor and evaluate their implementation of universal healthcare service financing.

\section{CONCLUSION AND RECOMMENDATIONS}

Strategic financing reforms equate to an efficient and clear delineation of the roles of government agencies. Further, resources beyond financial must not remain in the periphery of planning. Technological inputs for improved health information systems and capacity building of human resources must also be on the list. There is an agreement that the classification of individual-based and populationbased services should be set first, and identify the grey areas, before exploring the financing roles.

Based on the review of literature and roundtable discussion, the following are recommended:

1. Individual-based services should be funded by PhilHealth with assistance from the HMOs as deemed necessary. Population-based services shall be funded by $\mathrm{DOH}$ and grey areas should be identified and studied early on. For patients who have access to HMO benefits such as additional amenities and services, HMOs can cover these parts of the patient bill. 
2. The current role of HMOs should be noted in its financing assistance, wherein its target population is focused on corporate settings and those exclusively in the formal economy.

3. Revisit the current roles and evaluate the performance of the Local Health Boards. With the special health funds in the UHC Law, there should be specific rules on the Local Health Board's managerial and financial integration into the new system. Monitoring and accountability at the provincial level should also be emphasized.

4. Barangays and municipalities should submit their budget proposal to the local health boards, which will be subsequently deliberated upon by the provincial special health council. Hence, barangays and municipalities should develop their capacities to create strategic health investment plans.

5. There must be transparency and accountability in the utilization of Special Health Fund in funding health services to minimize fraud, duplication of services, and inefficiencies.

6. Implementation and facilitation of a stable health information system are needed to support a more efficient health service delivery system.

\section{Statement of Authorship}

All authors participated in data collection and analysis, and approved the final version submitted.

\section{Author Disclosure}

All authors declared no conflicts of interest.

\section{Funding Source}

This project was funded by the DOST DOH AHEADHPSR.

\section{REFERENCES}

1. National Health Insurance Act of 1995, Republic Act No. 7875. February 14, 1995.

2. Philippine Statistics Authority. Total health expenditures grew by 8.3 percent in 2018 [Internet]. 2019 [cited 2020 Jan 11]. Available from: https:// https://psa.gov.ph/pnha-press-release/node/144466.
3. Romualdez AG, dela Rosa JFE, Flavier JDA, Quimbo SLA, HartiganGo KY, Lagrada LP, David LC. The Philippine Health Systems Review. Geneva, Switzerland: World Health Organization [Internet]. 2011 [cited 2018 Nov 11]. Available from: http://www.wpro. who. int/philippines/areas/health_systems/financing/philippines_health_ system_review.pdf.

4. PhilHealth. Annual Report 2016. Securing and Protecting the Filipino's Helaht through and Innovative NHIP. 2016.

5. Villaverde M, Beltran M, Mamaril FR. Department of Health Annual Report 2018. Manila, Philippines: Health Policy Development and Planning Bureau-Department of Health.

6. Ulep and dela Cruz. 2013. Analysis of out-of-pocket expenditures in the Philippines. Philippine Journal of Development. Vol XL: 1,2.

7. Republic of the Philippines. Republic Act 11223. An Act Instituting Universal Health Care for All Filipinos, Prescribing Reforms in the Health Care System Amending for The Purpose Certain Laws, Appropriating Funds Therefore and for Other Purposes. 2018.

8. David LC, Ronquillo KG, Mamaril FR, Santos MS, Oras AM, Manongsong M, Rojas JF. Department of Health Annual Report 2016. Manila, Philippines: Health Policy Development and Planning Bureau-Department of Health [Internet]. 2017 [cited 2018 Oct 29]. Available from: https://www.doh.gov.ph/sites/default/files/ publications/2016\%20DOH\%20Annual\%20Report.pdf.

9. Tobe M, Stickely A, del Roasario R, Shibuya K. Out-of-pocket medical expenses for inpatient care among beneficiaries of the National Health Insurance Program in the Philippines. Health Policy Plan. 2013 Aug; 28(5):536-48.

10. PhilHealth. Stats and Charts 2018. [Internet]. 2018 [cited 2019 Nov]. Available from: https://www.philhealth.gov.ph > about_us > statsncharts > snc2018

11. PhilHealth Circular 2017-0006. Strengthening the Implementation of the No Balance Billing Policy (Revision1). 2017.

12. Tangcharoensathien, V, Patcharanarumol W, Ir P, Aljunid SM, Mukti AG, Akkhavong $\mathrm{K}$, et al. Health-financing reforms in southeast Asia: challenges in achieving universal coverage. Lancet. 2011 Mar; 377(9768):863-73. doi:10.1016/S0140-6736(10)61890-9.

13. Talampas RG. Review of Experience of Social Health Insurance in Three Asian Countries: China, Thailand, and Vietnam (No. 201446). PIDS Discussion Paper Series [Internet]. 2014 [cited 2018 Nov 20]. Available from: https://dirp3.pids.gov.ph/webportal/CDN/ PUBLICATIONS/pidsdps1446.pdf.

14. Hsiao W, Shaw RP. Social health insurance for developing nations. The World Bank. 2007. doi: 10.1596/978-0-8213-6949-4.

15. World Bank Group. Health financing revisited: Risks pooling mechanisms [Internet]. n.d. [cited 2018 Oct 15]. Available from: http://siteresources.worldbank.org/INTHSD/Resources/topics/ Health-Financing/HFRChap3.pdf. 